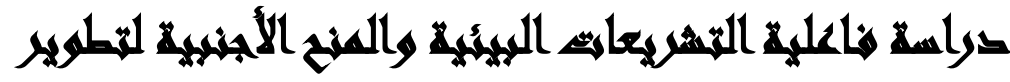

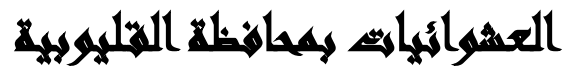

\section{[iv]}

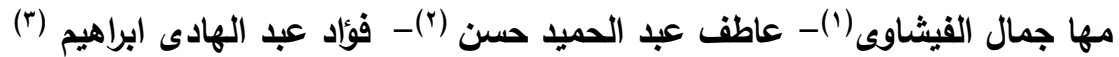

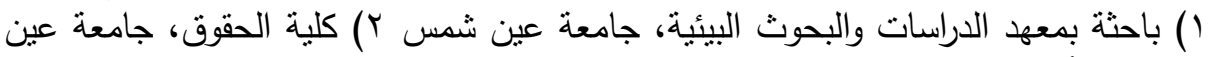
شمس r) أكاديمية المستقبل

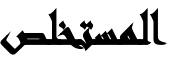

تعد ظاهرة العشوائيات فى مصر ، من أحد أهم التحديات التي تهدد الدولة المصرية وذللك التهائ

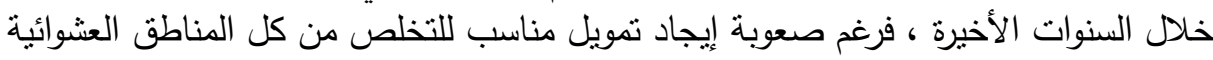

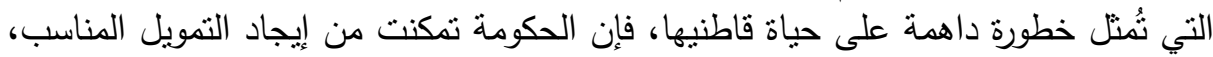

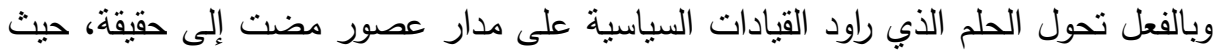

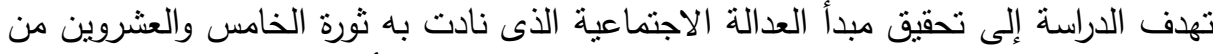

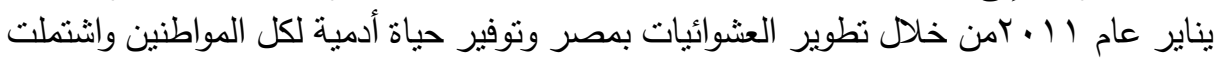

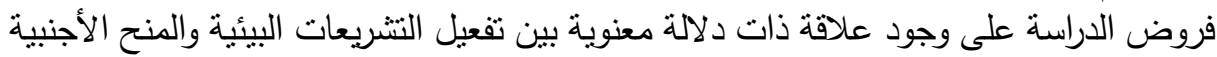
لتطوير العشوائيات بمحافظة القليوبية. وذللك من خلال تفعيل شراكة الدول المانحة مع كل من السلطة المختصة والمثنلة في

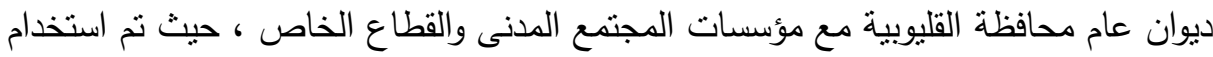

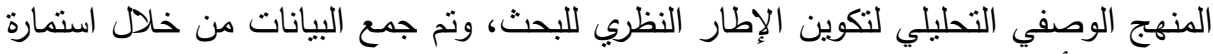

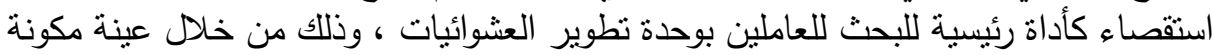

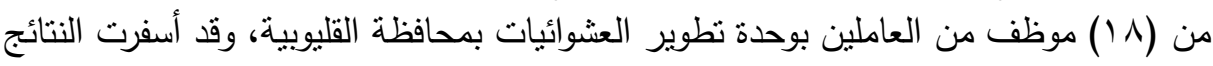

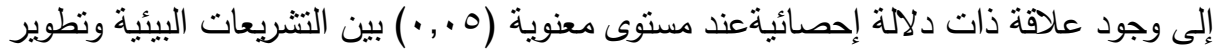

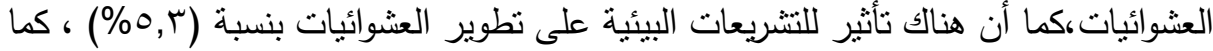

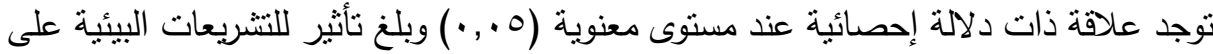

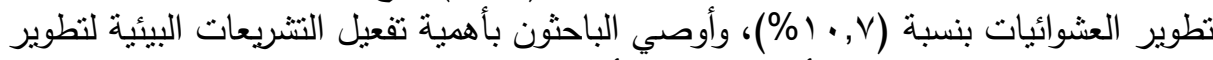

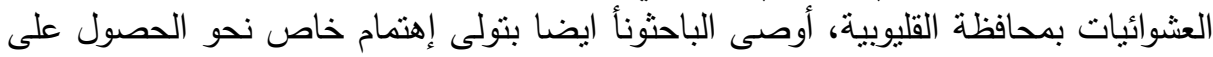

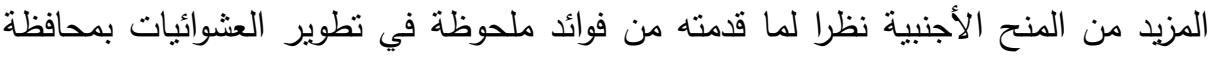




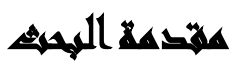

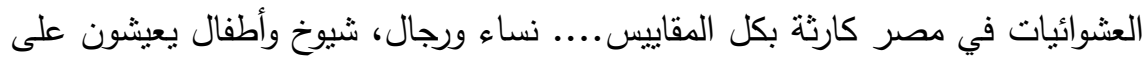

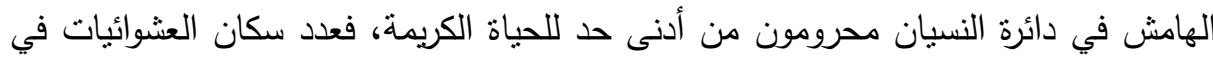

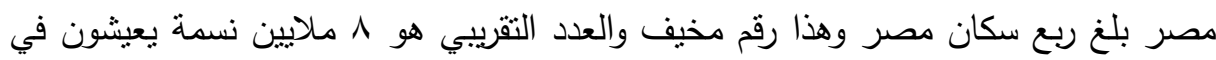
11 منطقة عشوائية على مستوى الجمهورية(تقرير الجهاز المركزى للتعبئى العامة والاحصاء)

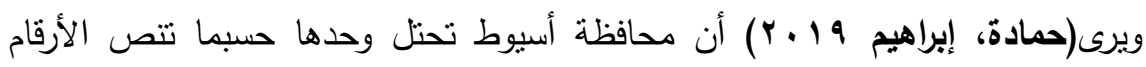
الرسمية نصيب الأسد تليها القاهرة الكبرى ونثمل القاهرة والجيزة والقليوبية وبما أنني من أبناء

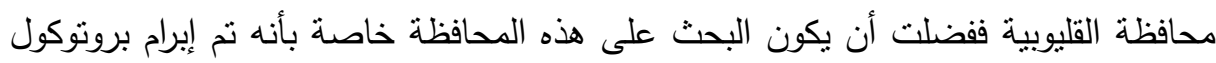

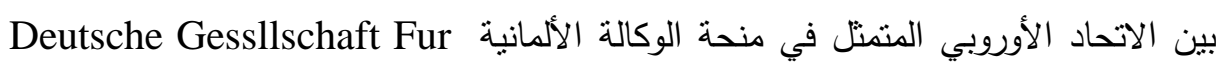
Internationale Zusammenarbeit (GIZ) GmbH - التي تستهدف دعم وتدريب العاملين بوحدة نطوير العشوائيات بالمحليات بالتدريب والتعلم

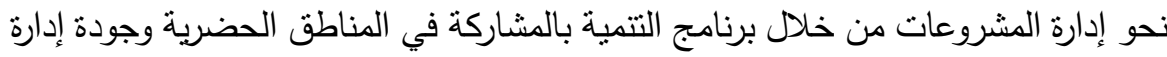

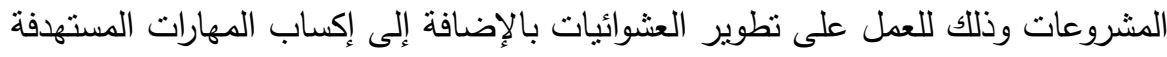

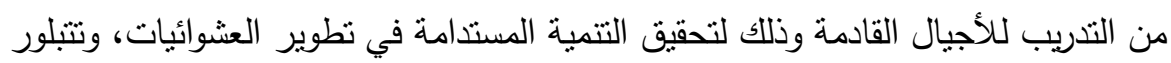

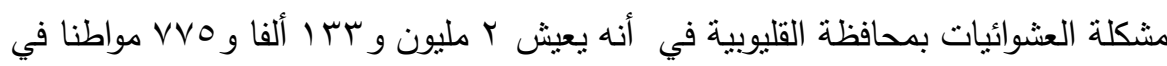

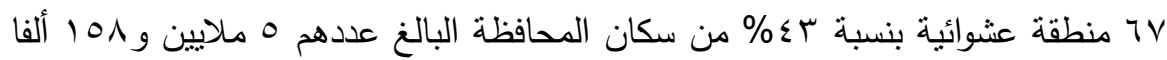

$$
\text { و ؟ ؟ ب نسمة(الجهاز المركزى للتعبئة العامة والاحصاء). }
$$

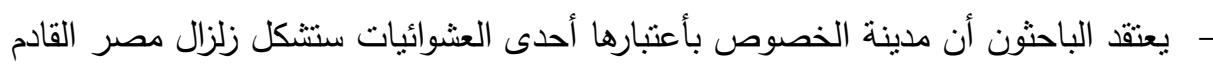

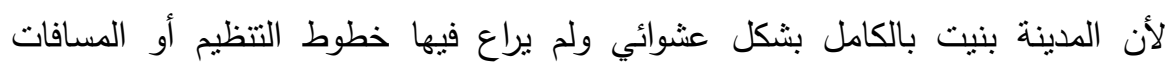

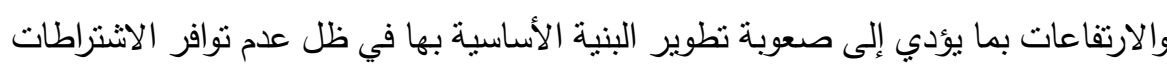

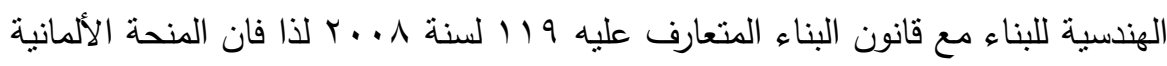

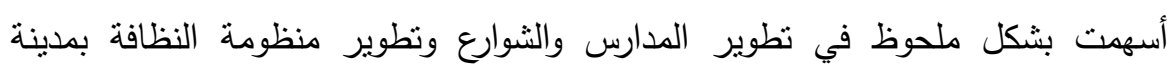

$$
\text { الخصوص مما كان لهو مردود إيجابى على المواطنين. }
$$

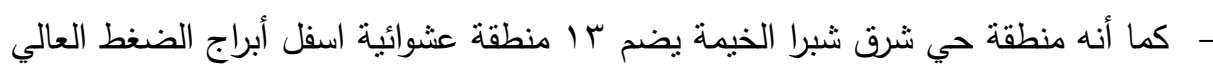

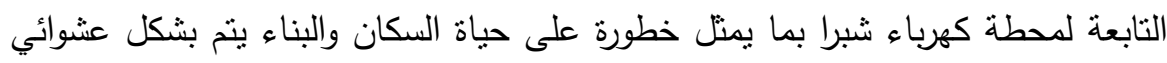

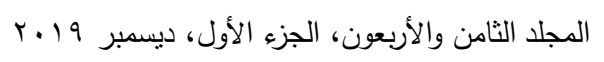


وأنه تم اختيار منطقة عبد المنعم رياض بشبرا الخيمة بكثافة سكانية حوالي . ب ألف نسمة

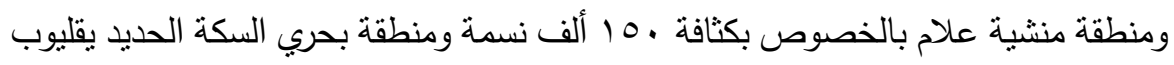

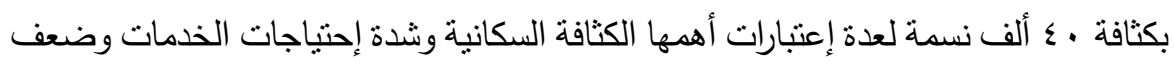

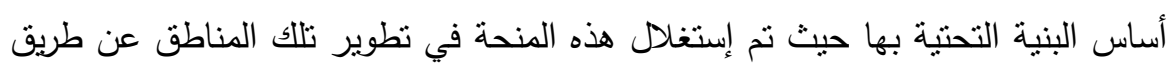
دراسة المكان من كل جوانبه وتطبيق منهج التتمية بالمشاركة والارتقاء بمستوى الخدمات

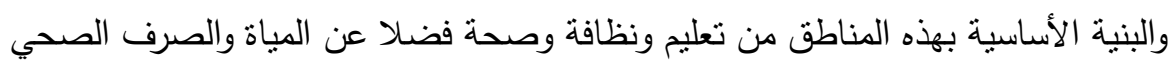
وتطوير الوحدات الصحية بمنشية عثمان ونوبار وتطوير منظومة النظافة. - - أما مدينة قليوب فيوجد بها ترع ملوثة بمخفات الصرف الصحى والقمامة والحيوانات النافقة

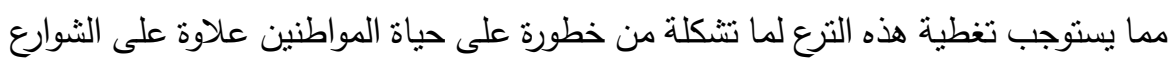
الغير مرصوفة مما يعوق حركة المارة مما يستوجب رصف هذه الثوارع ببلاط الانترلوك هنك بالإضافة الى توفير معدات حديثة لمنظومة النظافة و تشجير الثوارع وعمل حديقة للأطفال

ومكتبة عامة.

فقد عقدت المحافظة إجتماعا مع عدد من أعضاء الوكالة الألمانية بالقاهرة ومسئولي إدارة

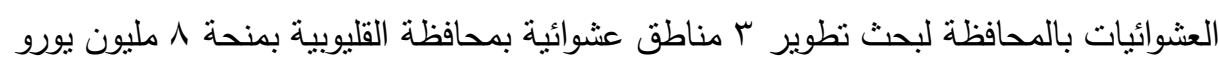

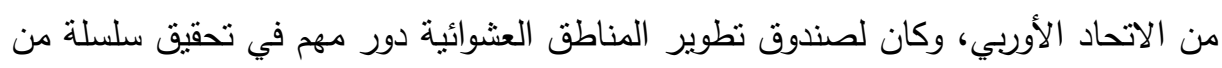
الإنجازات بمختلف محافظات الجمهورية.

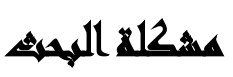

تتمثل مشكلة البحث فيما يلي: وجود قصور فى تطبيق نصوص التشريعات البيئة بالاضافة

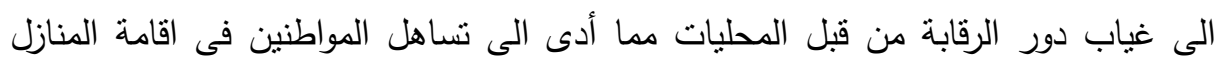

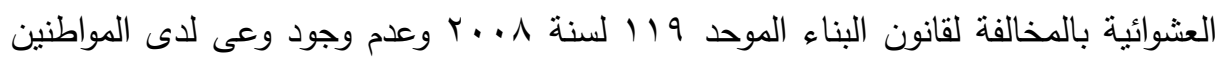

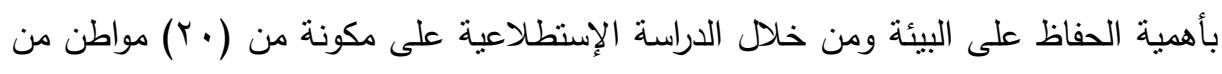

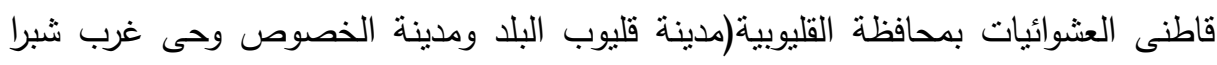

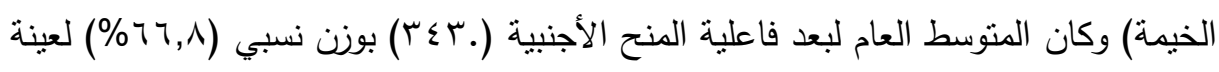

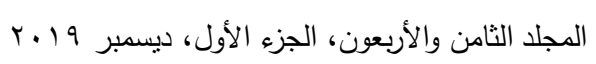




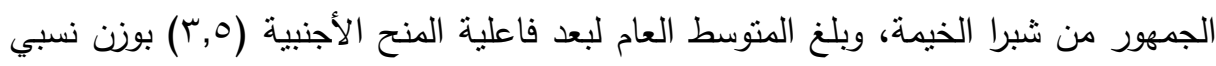

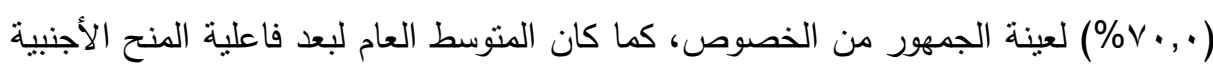

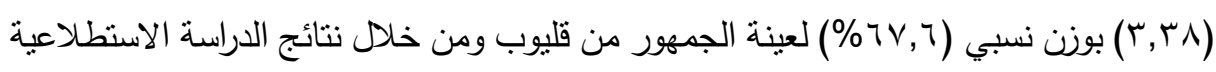

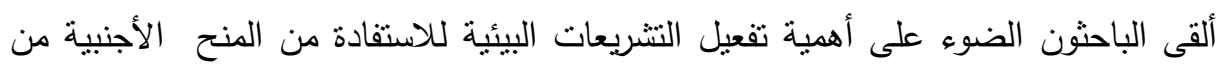
الاتحاد الاوبى والمتنتلة فى منحة الوكالة الالمانية لنطوير عشوائيات محافظة القليوبية.

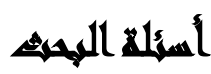

يمكن بلورة مشكلة البحث فى الأسئلة الآتية:

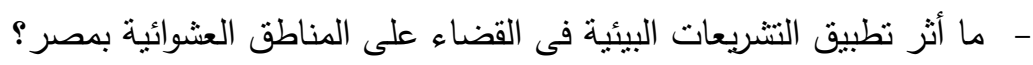
- ما أهية الاستفادة من المنح والمساعدات الاجنبية فى تطوير العشوائيات بمحافظة القليوبية؟ - ما دور الجمعيات اللأهلية فى تطوير المناطق العشوائية؟ الأنج

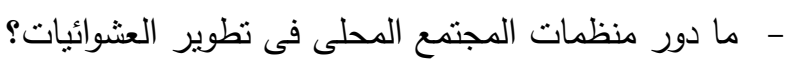

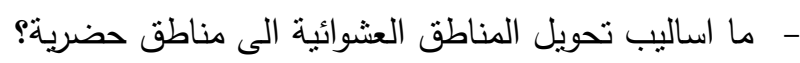

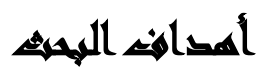

يهاف البحث إلى تحقيق الأهداف التالية: حيث يهدف إلى تحقيق هدف رئيسى بجانب مجموعة

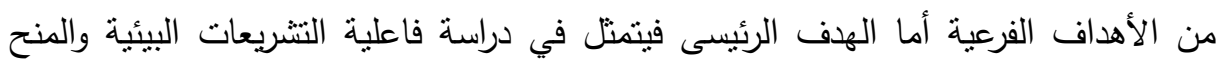

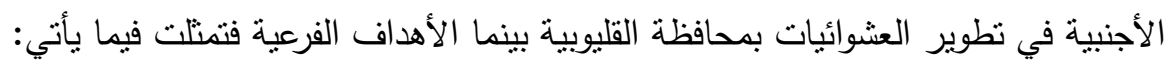

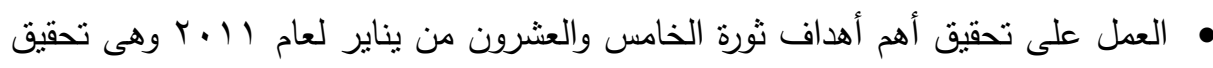

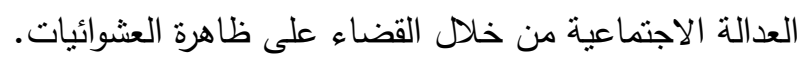
• • العمل على تفعيل التثريعات البيئية الحالية لنطوير العشوائيات بمحافظة القليوبية.

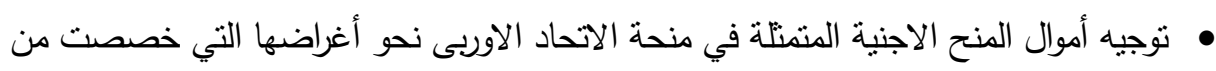
اجلها. • التعرف على اهم التحديات التي تواجه العاملين بوحدات تطوير العشوائيات وسبل مواجهتها. 
• تلبية الاحتاجات الأساسية للجمهور المستهدف من قاطنى المناطق العشوائية من خلال

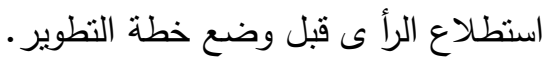
• رفع كفاءة العاملين بوحدات تطوير العشوائيات والجمهور المستهدف بأهمية النشريعات البيئية المعمول بها في مصر (مثل قانون حماية البيئة رقم ؛ لسنة ـ99 199 وتعديلاته ولاتحته التتفيذية) وجزاء مخالفة قواعدها. •القاء الضوء على أهمية برنامج التتمية بالمشاركة من خلال تضافر جهود منظمات المجتمع وداءع المدنى مع العاملين بوحدات تطوير العشوائيات.

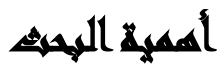

يمثل هذا البحث درجة من الأهمية على عدة مستويات: 1- المستوى المهني أو العلمي: يتم تفعيل النتريعات البيئية والاستفادة من المنح والمساعدات الأجنبية لتطوير المناطق العشوائية بمحافظة القليوبية تمهيدا للقضاء عليها. r- المستوى العلمي أو الأكاديمي: إضافة بعد جديد حيث أن تفعيل النتريعات البيئية والاستفادة من المنح والمساعدات من المنوقع أن يلعب دورا كبيرا في تطوير العثوائيات بحافظة القليوبية.

r-المستوى الشخصي للباحثة: إن الباحثون من أبناء محافظة القليوبية ومن العاملين بوحدة تطوير العشوائيات لذا فمن المنوقع أن يساعد هذا البحث في الوقوف على معوقات

تفعيل التشريعات البيئية والمنح الأجنبية لنطوير العشوائيات بمحافظة القليوبية.

\section{Aas}

$$
\text { تتمنل حدود البحث في الآتي: }
$$

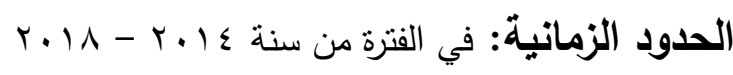
الحدود المكانية: تطبق الدراسة على محافظة القليوبية المتمنلة في عشوائيات (مدينة قليوب-

$$
\text { مدينة الخصوص - حي غرب شبرا الخيمة). }
$$




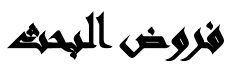

1-توجد علاقة ذات دلالة معنوية بين التشريعات البيئية وتطوير العشوائيات بمحافظة القليوبية. r-توجد علاقة ذات دلالة معنوية بين أموال المنح الأجنبية وتطوير العشوائيات بمحافظة دلئة

القليوبية.

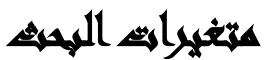

يتبنى البحث الحالي نموذجا افتراضيا يعبر عن التأثير المنطقية بين المتغيرات المستقلة

والمتغير التابع حيث أن البحث يحتوي على أكثر من متغير مستقل ومتغير تابع حيث يتم اعنبار

فاعلية النتريعات البيئية عينة البحث متغير مستقلا يؤثر في المتغير التابع وهو نطوير

العشوائيات بمحافظة القليوبية .

• • • المتغير المستقل فاعلية التشريعات البيئية.

• • المتغير التابع تطوير العشوائيات بمحافظة القليوبية ـ

كذلك تم اعتبار المنح الاجنبية عينة البحث منغيرا مسنقلا ممثلا في منحة الوكالة الألمانية

ويؤثر في المتغير التابع وهو تطوير العشوائيات بمحافظة القليوبية. • • المتغير المستقل المنح الاجنبية.

• المتغير التابع تطوير العشوائيات بمحافظة القليوبية.

يتم اعتبار الهنح الاجنبية عينة البحث متغيرا مستقلا يؤثر في المتغير التابع وهو نطوير

العشوائيات بمحافظة القليوبية.

برنامج التنمية بالمشاركة في المناطق الحضرية مؤسسة تكامل لاستدامة التتمية

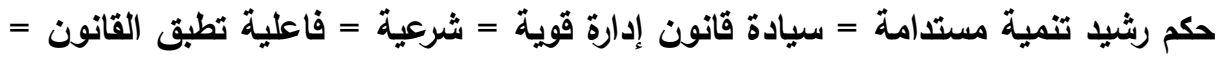

مجتمع قابل للتغيير والتطور - مشاركة فاعلة. 


\section{الصراسايت الساريها}

الاراسات المتعلقة بالتشريعات البيئية: ا ـ دراسة (Wilson, C.D.H,2011): يتمنل الهدف هنا في دراسة مستوي الاداء القانوني

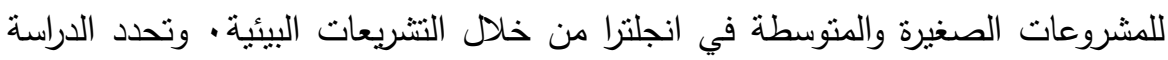
مستوي الالتزام بالتشريعات القانونية، ناثير وفعالية التشريعات البيئية وكيفية تطوير نظم الضبط الالنزام البيئي بالنسبة للمشروعات الصغيرة والمتوسطة ـ لقد تضمنت الدراسة مجموعة كبيرة من التشريعات البيئية، بما في ذلك ادارة ونقل المخلفات، الاستثناءات والاعفاءات

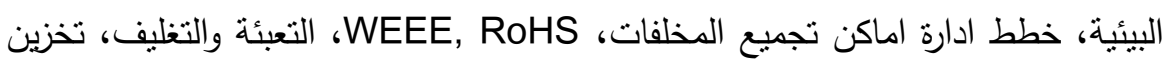
البترول والجرائم البيئية الاخري المحتملة . لقد تمت مراقبة مدي الالنزام بالتشريعات البيئية بالنسبة ل ع ـ مشروع صغير ومتوسط في ه قطاعات مختلفة شمال غرب انجلترا • كما تم اجراء مقابلات شخصية مع ادارة الSME، الموظفين، المعنيين بعملية التنظيم، مسئولي

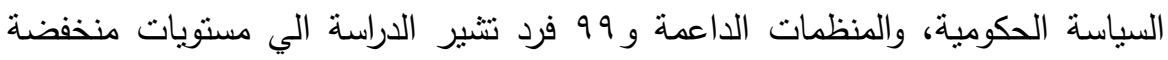
للالتزام بنص وروح القانون، انخفاض مستوبي وعي وفهم النتريعات البيئية، عدم قيام مشروع دئي واحد او منظمة داعمة او معني بعملية التنظيمة بتقدير الالتزام البيئي بصفة عامة، انخفاض ولتصني مستوي عمليات المراقبة المعنية بالمشروعات الصغيرة والمتوسطة، تمت المعبه المبالغة في الاشارة الي تاثير التشريعات البيئية بالنسبة للSمEs.

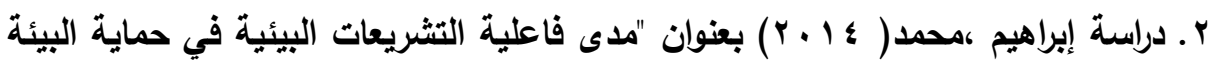

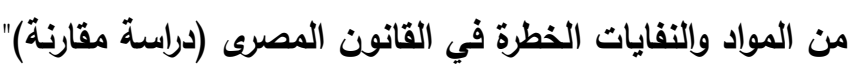
هدفت الدراسة إلى: النفايات الخطرة في ضوء القانون المصرى من خلال دراسة مقارنة لتوضيح الفرق بين التشريعات البئية للدول المتقدمة والافريقية والعربية والمصرية. تحديد وتقييم ملامح السياسة التشريعية للوقوف على مدى كفائتها في الحفاظ على البيئة من المواد والنفايات الخطرة وقدير مدى ملائمة العقوبات التي أقرها المشرع للمخالفات البيئية من المواد والنفايات الخطرة وتقدير مدى ملائمة العقوبات التي أقرها المشرع للمخالفات البيئية ومدى مناسبتها لظروف المجتمع مع التوصية بنطويرها وتعديلها إذا لزم الأمر . 
دراسات تتعلق بالمنح الجنبية:

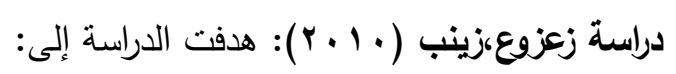

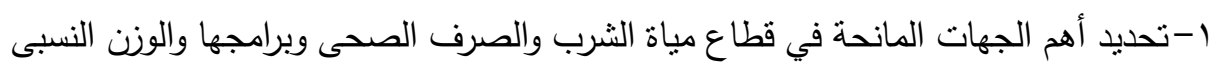

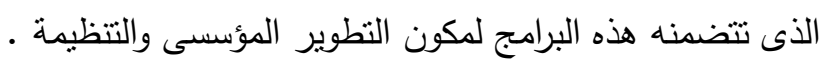

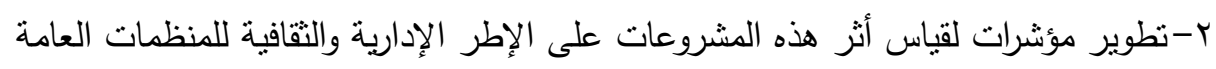

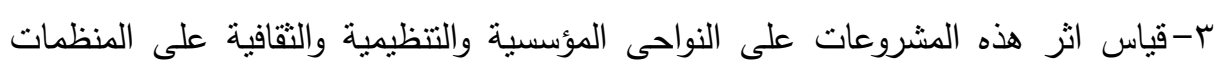
العامة. ع-نطوير نموذج إسترثنادى للتعاون الفني والمالى بين الدول الصناعية والدول الاخذه في النمو

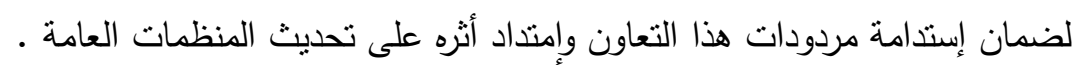

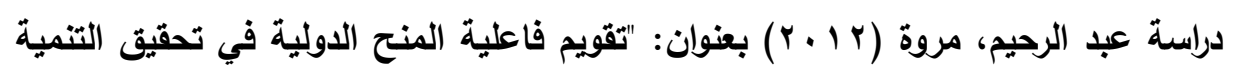

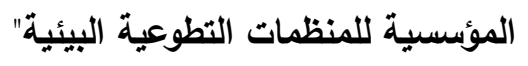

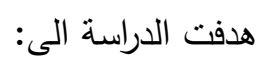
ا ـ قياس مستوى تحقيق فاعلية المنح الدولية في تحقيق التتمية المؤسسية للمنظمات النطوعية البيئية. r. تحديد الصعوبات التي تقلل من تحقيق فاعلية المنح الدولية للتتمية المؤسسية في الدنظمات التطوعيى البيئية. r. التوصل إلى إستراتيجية مقترحة لزيادة إستفادة المنظمات التطوعية البيئية من المنح الدولية

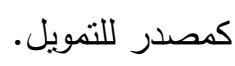

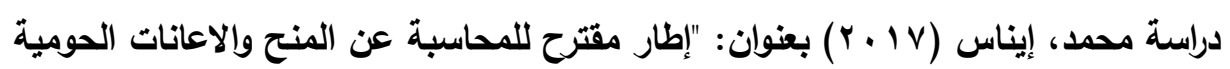

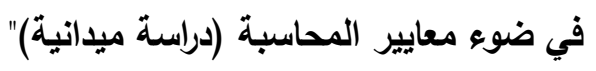

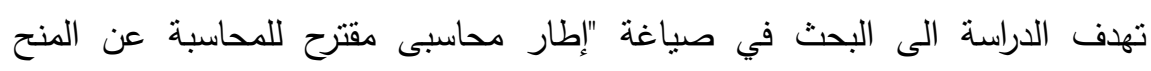

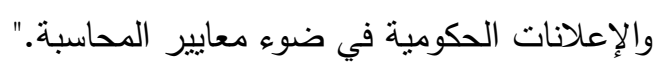

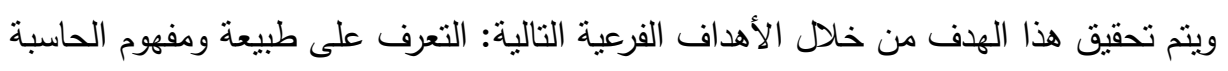

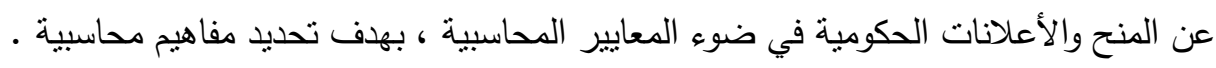


دراسة مدى القدرة على تطبيق إطار محاسبى متكامل للمحاسبة عن المنح والأعلانات الحكومية في ضوء معايير المحاسبة الدولية وما يقابلها من معايير مصرية. تثنير نتائج الدراسة إلى أنه من الضرورى بناء إطار للمحاسبة عن المنح والأعلانات الحكومية، كما يوفر الإطار المحاسبى المقترح نتائج تحقق خصائص جودة المعلومات المحاسبية ويوفر المعلومات الملائمة لإدارة الثركات بغرض إتخاذ القرارات للمساهمين والمستثرين الذين يرغبون في التعامل مع الثركات الاستثمارية المختلفة وللجهات الرقابية المتعددة، ولغيرها من

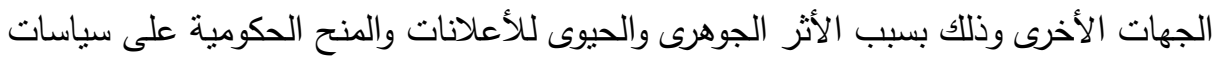
الثركة واستمراريتها ونموها ، وللحاجة الضرورية إلى قياسها وعرضها والإفصاح عنها بقوائم

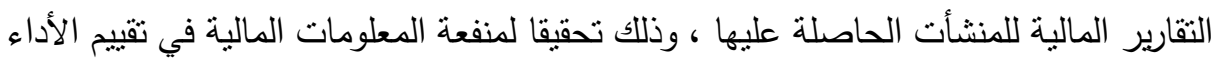
وترشيد إتخاذ القرارات عند أدنى تكلفة ممكنة ، ومن أجل تحقيق منافع التتسيق بين سياسات

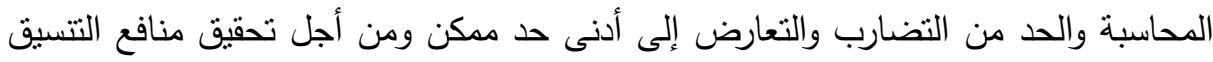
بين سياسات المعالجة المحاسبية والحد من التضارب والتعارض إلى أدنى حد ممكن. دراسات تتعلق بتطوير العثوائيات:

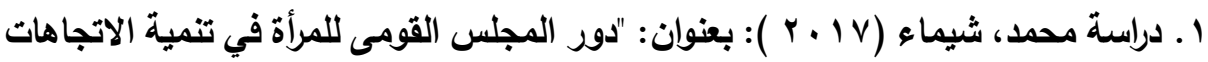

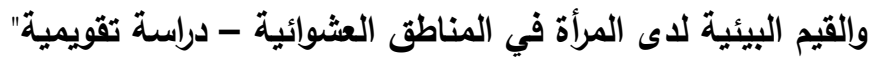

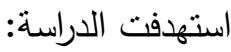
1- التعرف على ظاهرة المناطق العشوائية وأسباب نشأتها والمشكلات التي تتتج عنها وأنماطها وخصائص سكانها . بان

r-التعرف على الوضع الحالي للقضايا البيئية التي تعانى منها المرأة في المناطق العشوائية . .

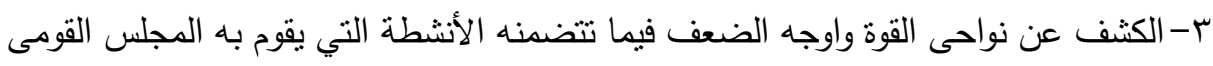

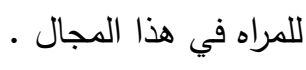
ع-تتمية الإتجاهات والقيم البيئية لاى المرأهة في المناطق العشوائية . 


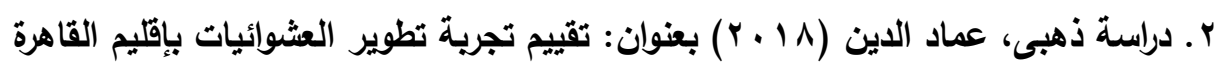

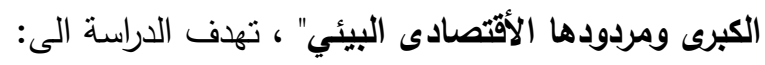

1-التعرف على ظاهرة العشوائيات عالميا والتعريفات المختلفة لقضية الأسكان غير الرئئ الرسمي

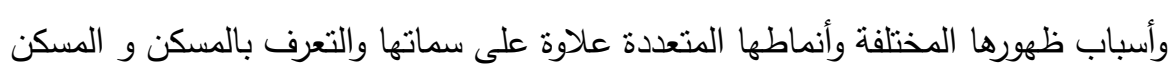

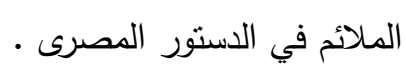

r-دراسة نظرية وتشتمل على خلفية نظرية لقضية المناطق الإسكان غير الرسمي في مصر

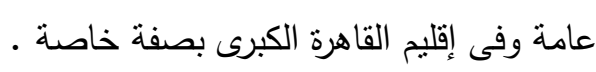

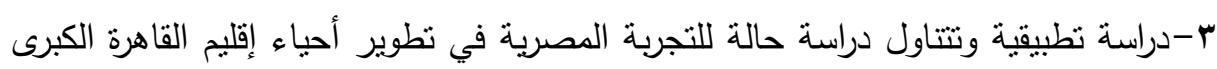
من خلال تقييم ثلاث حالات دراسية .

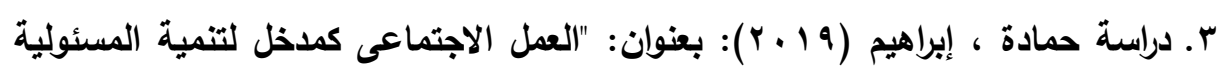

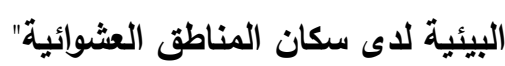

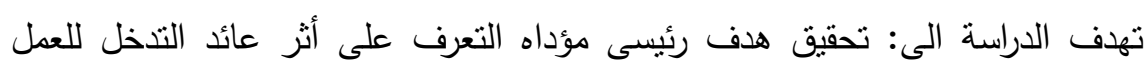

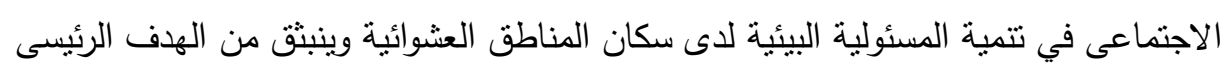

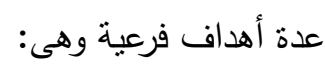

ا. التعرف على أثز عائد التدخل للعمل الإجتماعى وتتمبة الوعى البيئي لدى سكان المناطق

$$
\text { العشوائية. }
$$

r. التعرف على أثز عائد التخل للعمل الإجتماعى وزيادة إهتمام سكان المناطق العشوائية

$$
\text { للمحافظة على البيئة من التلوث. }
$$

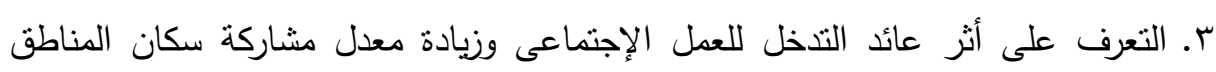

$$
\text { العشوائية في الحفاظ على البيئية من التلوث. }
$$




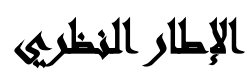

$$
\text { أود أن أعرف متغيرات الدراسة فيما يلي: }
$$

1 ـ مفهوم الفاعلية: يوجد العديد من التعريفات الخاصة بالفاعلية نذكر منها الآتي:

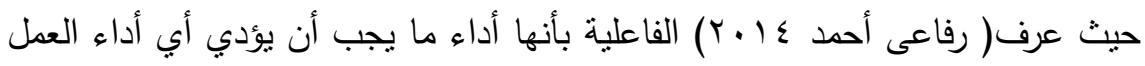

$$
\text { المناسب الذي يجب أداءه لبلوغ الأهداف المحددة. }
$$

التطوير: يعني التغيير أو التحويل من طور إلى طور وتعني كلمة تطور لا تحول من طوره "تعني كلمة التطور" التغير التدريجي الذي يحدث في بنية الكائنات الحية وسلوكها ويطلق أيضًا على أن التغير التدريجي الذي يحدث في تركيب المجتمع أو العلاقات أو النظم أو القيم السائدة

التطور اصطلاحًا هو: التحسين وصولا إلى تحقيق الأهداف المرجوة بصورة أكثر كفاءة.

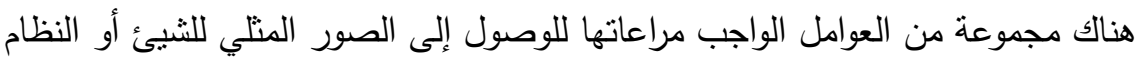
أو المنهج المراد نطويره كما يلي:

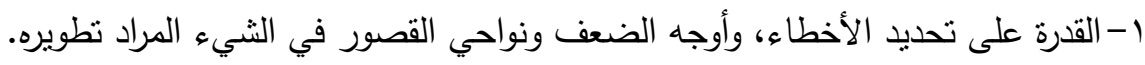

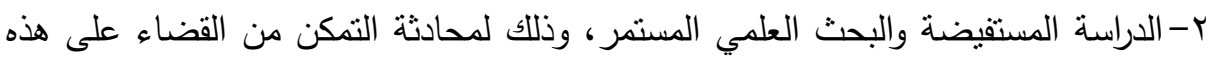

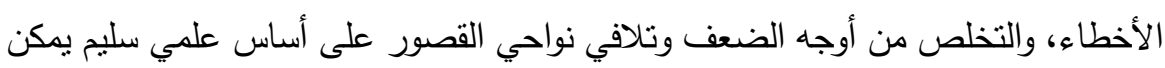

$$
\text { من إحداث عملية التحسين المقصودة. }
$$

ب-الأخذ بالأحداث والاتجاهات العالمية والاستفادة من خبرات الآخرين الذين قطعوا أشواطًا

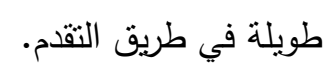

r. المقصود بالتشريعات البيئية: يطلق لفظ قانون على معنيين أحدها واسع والآخر ضيق فالقانون بالمعنى الواسع Droit هو مجموعة القواعد التي تتظم سلوك الافراد في

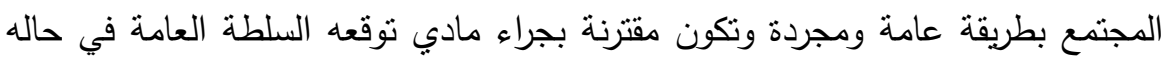

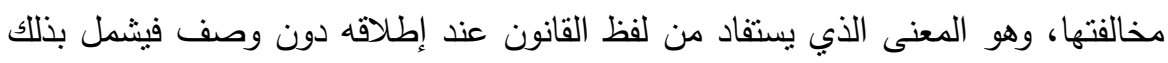
كل قاعدة تهدف إلى تتظيم سلوك الإنسان في المجتمع سواء كان مصدر هذه القدئه القاعدة

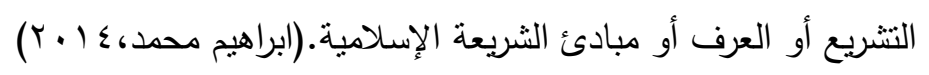

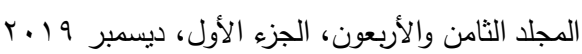


أما القانون بالمعنى الضيق Loi فيراد به مجموعة القواعد القانونية التي من السلطة

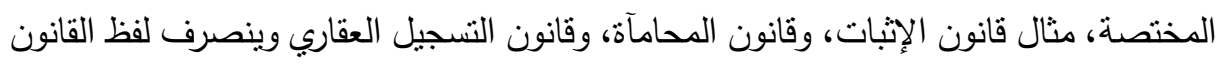

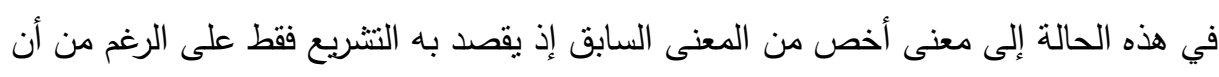

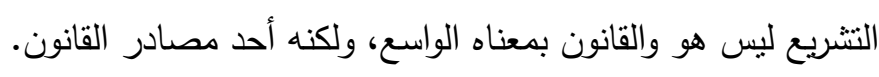

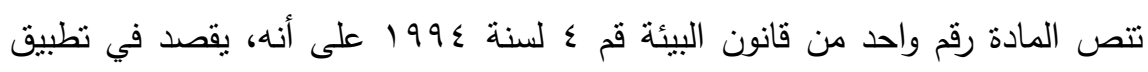

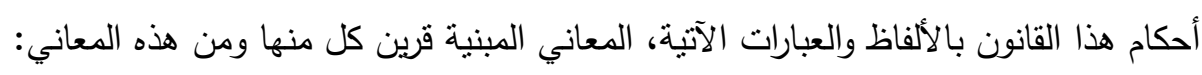

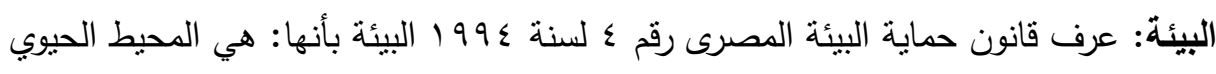

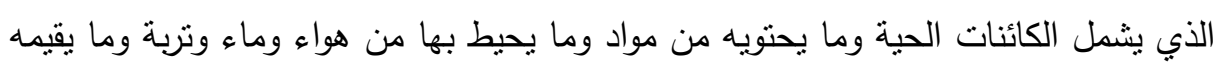
الإنسان من منثآت. ץ.تعريف المنح والمساعدات الأجنبية: لقد انتشر استخدام اصطلاح المعونه أو من المساعدات الاقتصادية الخارجية أو الدولية، ولكن هناك اختلاف كبير في مدلوله وتعريفه، حيث الإنيله: انه من الممكن أن يختلف التعريف الحقيقى للمعونه، والمقصود من ورائها بين الدول المانحه بعضها البعض، أو بين الدول المانحة والوكالات الخاصة.

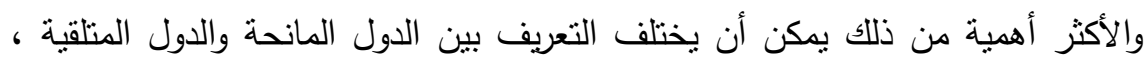

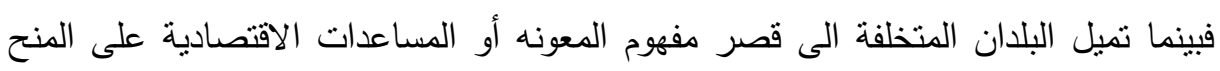

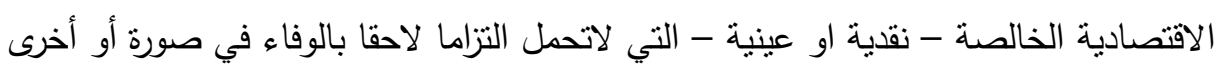

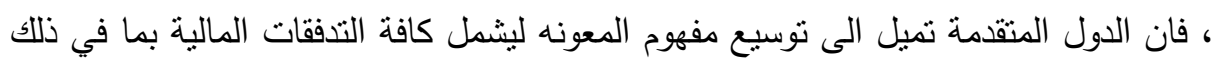

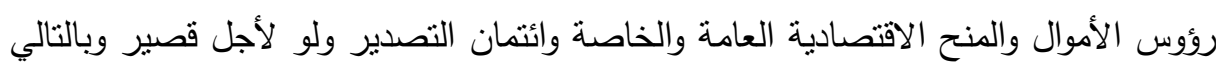

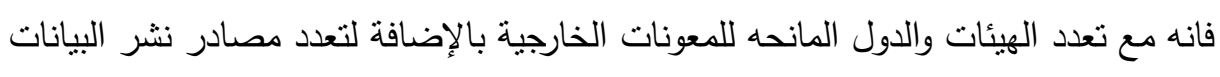
والمعومات المتعلقة بها فيعرف البعض المنح والمعونات الاقتصادية على أنها " الموارد

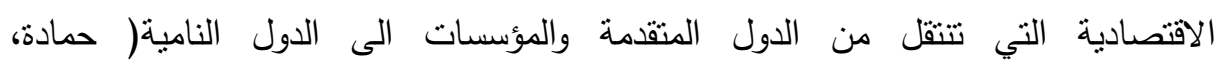

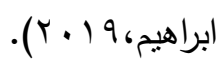




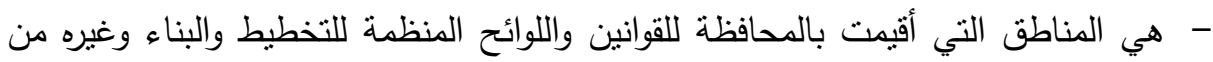

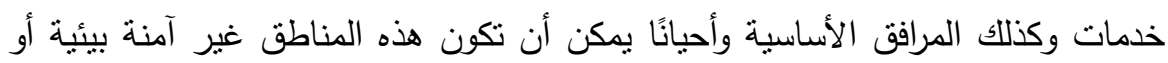

$$
\text { اجنماعيًا. }
$$

- وتم تصنيف المناطق إلى مناطق غير مخططة ومناطق غير أمنة.

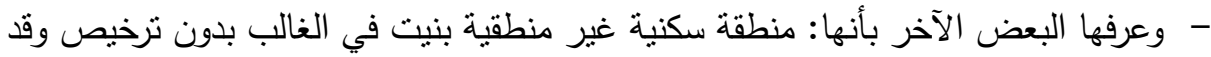
تنقتر لأبسط مقومات الحياة الكريمة، كما تسمي في مصر وفي الجيات الجزائر البناء القصديري

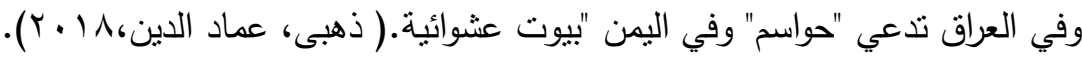

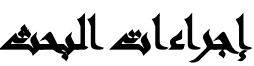

• تم تصميم أداة البحث وهي استمارة استيان مكون من (؟) أبعاد (التنتريعات البيئية) و (فاعلية المنح الأجنبية) و (تطوير المشروعات) وقد بلغت عدد العبارات (10) عبارة العنات. • عينة البحث: تم تطبيق الاستيان على عدد (1) من العاملين بوحدات نطوير العشوائيات

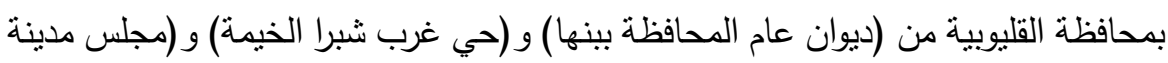

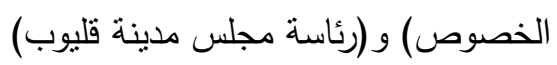
• ثبات الاستبيان: للنحقق من ثبات الاستيبان استخدم الباحثون معادلة ألفا كرونباخ

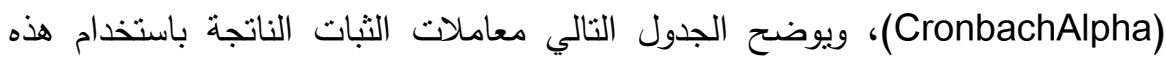

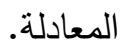


جلول (1) (1) ثبات العبارات لأبعاد الاستبيان

\begin{tabular}{|c|c|c|}
\hline معامل ثبات ألفا & عدد العبارات & أبعاد الاستبيان \\
\hline$\cdot, 7 \leqslant V$ & 0 & التشريعات البيئية \\
\hline., $0 \wedge 9$ & 0 & فاعلية المنح الأجنبية \\
\hline$\cdot, 77 \varepsilon$ & 10 & تطوير المشروعات \\
\hline$\cdot, T \leqslant T$ & TO & إجمالي الاستبيان \\
\hline
\end{tabular}

أ- - يتضح من الجدول السابق أن قيم معاملات الثبات لأبعاد الاسنبيان جميعها قيم جيدة حيث

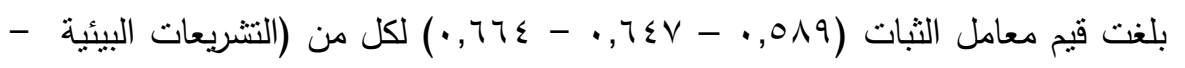

فاعلية المنح الأجنبية - تطوير المشروعات) على التوالي، وكانت قيمة ألفا لإجمالي

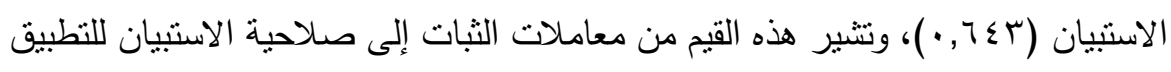

وإمكانية الاعتماد على نتائجه والوثوق به.

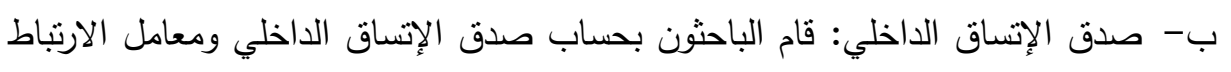

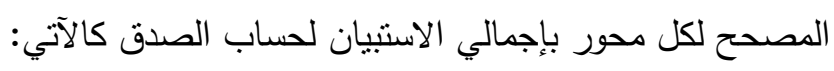
جدول (ץ): ثبات العبارات لأبعاد الاستبيان

\begin{tabular}{|c|c|c|c|}
\hline الدلالة المعنوية & معامل الارتباط & \multicolumn{2}{|c|}{ أبعاد الاستبيان } \\
\hline$\cdot, \ldots$ & $\left({ }^{(* *)} \cdot, v \cdot 1\right.$ & معامل ارتباط بيرسون & التشريعات البيئية \\
\hline$\cdot, \ldots 1$ & $(* *) \cdot, \_q r$ & معامل ارتباط بيرسون & فاعلية المنح الأجنبية \\
\hline$\cdot, \cdots 1$ & $($ (**),,$\vee \wedge \circ$ & معامل ارتباط بيرسون & تطوير المشروعات \\
\hline
\end{tabular}

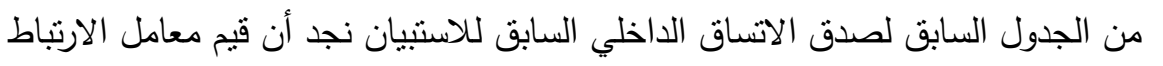

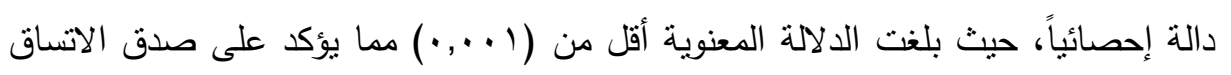

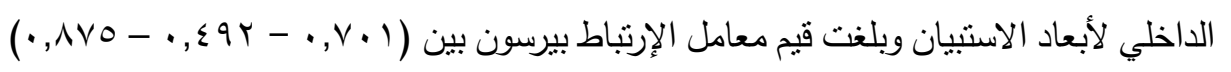

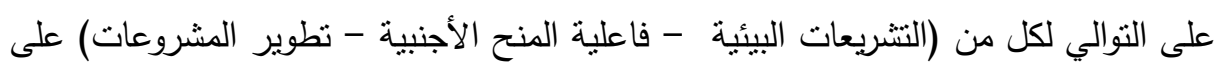
التوالي، وهي قيم تؤكد على صدق الاستبيان. 


\section{منهمبي البهميد}

من أجل تحقيق أهداف البحث قامتالباحثون بإتباع الدنهج الوصفي والأسلوب الاستقرائي

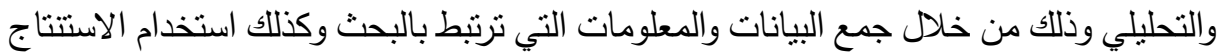
الهنطقي وذلك من خلال تحليل مشكلة البحث وأبعادها وذلك عن طريق الكيق الاستعانة بالآتي:

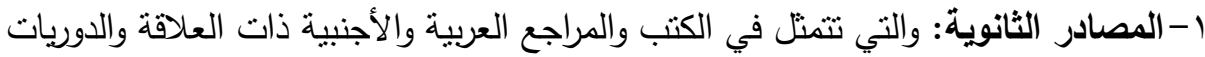

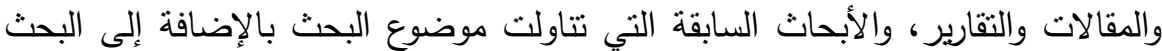
والمطالعة في مواقع الانترنت المختلفة.

r-المصادر الأولية: والتي تتمثل في جمع البيانات الأولية من خلال سحب عينة من مدن محافظة القليوبية (مدينة قليوب- مدينة الخصوص- مدينة شبرا الخيمة)

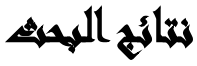

التحليل الإحصائي: تم تفريغ البيانات عن طريق البرنامج الإحصائي المعروف برنامج الحزم الإحصائية للعلوم الاجتماعية Statistical Package For Social Sciences ونم النحليل

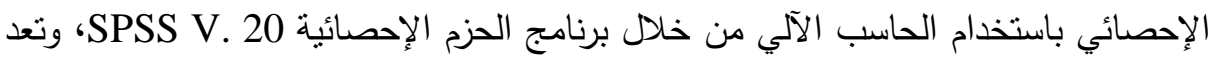

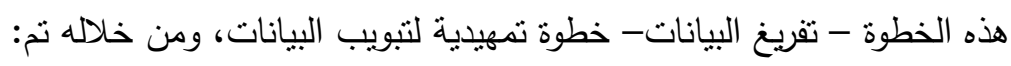
1-اختبار الثباتمن خلال معامل ألفا كرونباخ CronbachsAlpha لاختبار ثبات متغيرات

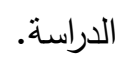

ץ-اختبار صدق الإتساق الداخلي من خلال معامل إرتباط بيرسون بين أبعاد الدراسة وإجمالي

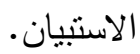

r- الإحصاءات الوصفية للبيانات من خلال جدولة البيانات في صورة جداول (المتوسط الحسابي

$$
\text { والإنحراف المعياري) لدنغيرات الدراسة. }
$$

ع-تحليل الانحدار البسيط والمتعدد لدراسة فاعلية النتريعات البيئية والمنح الاجنيبة لتطوير العشوائيات بمحافظة القليوبية. 


\section{التحقق من صحة فروض الاراسة:}

الفرض الأول: توجد علاقة ذات دلالة معنوية بين التشريعات البيئية وتطوير العشوائيات بمحافظة القليوبية.

جدول (r): اختبار الانحدار البسيط لمدى تأثير النتريعات البيئية على تطوير العشوائيات

\begin{tabular}{|c|c|c|c|c|c|c|}
\hline المعنوية & قيمة ف & التحديد معامل & $\mathbf{R}$ & قيمة ت & قيتية & المتغيرات \\
\hline$\cdot, \cdot r$ & $r, q \cdot 1$ & r.,. & $\cdot, r M$ & $r, \wedge 9 \vee$ & 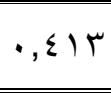 & التشريعات \\
\hline
\end{tabular}

يتضح من الجدول السابق لتحليل الانحدار الخطي البسيط أن قيمة معامل الارتباط (R)

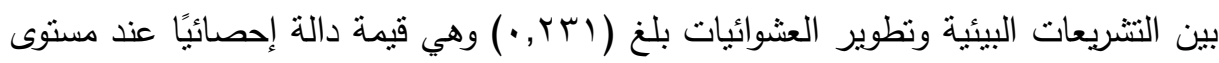

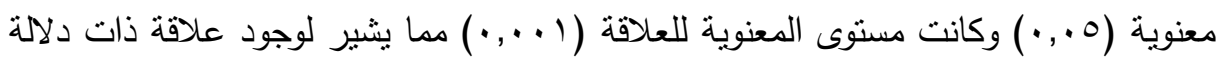

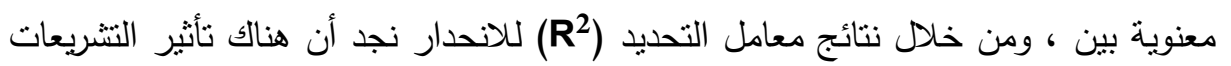

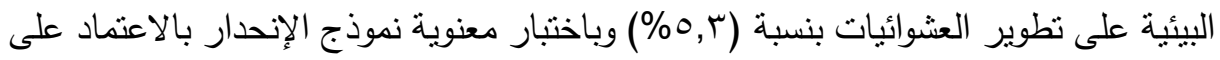

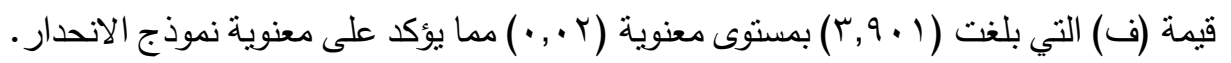
تم من خلال النموذج اختبار معنوية معامل الانحدار (B) والذي يوضح وجود علاقة طردية

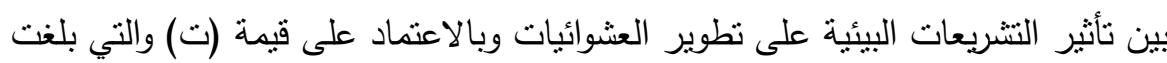

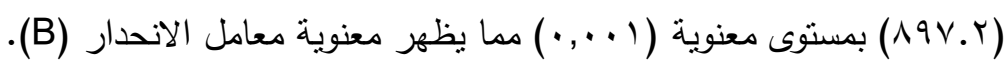

الفرض الثاني: توجد علاقة ذات دلالة معنوية بين المنح الأجنبية وتطوير العثوائيات بمحافظة

القليوبية.

جدول (ء): اختبار الانحدار البسيط لمدى تأثثر المنح الأجنبية على تطوير العشوائيات

\begin{tabular}{|c|c|c|c|c|c|c|}
\hline المعنوية & قيمة ف & التحديد معامل & $\mathbf{R}$ & قيمة ت & قبيمة & المتغيرات \\
\hline$\cdot, \ldots 9$ & $7, \wedge \uparrow \wedge$ &., $1 \cdot V$ & . TYV & $r, 1 \cdot 1$ &., $0 . r$ & لمنح لأجنبية \\
\hline
\end{tabular}

يتضح من الجدول السابق لتحليل الانحدار الخطي البسيط نجد أن قيمة معامل الارنباط

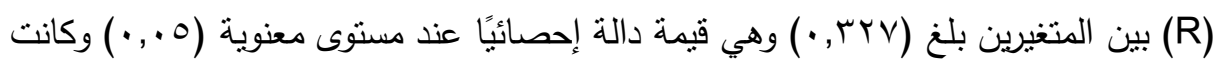

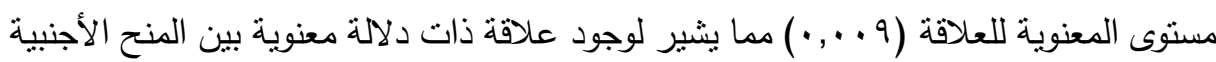

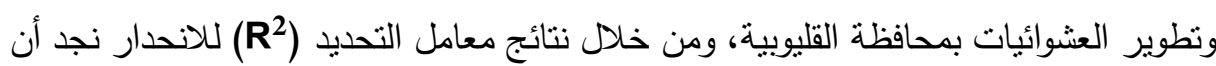


هناك تأثثر للتشريعات البيئية على تطوير العشوائيات بنسبة (v, • ( \%) وباختبار معنوية نموذج

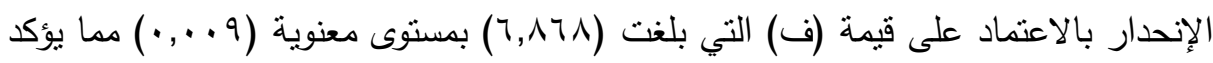
على معنوية نموذج الاتحدار .

تم من خلال النموذج اختبار معنوية معامل الانحدار (B) والذي يوضح وجود علاقة طردية

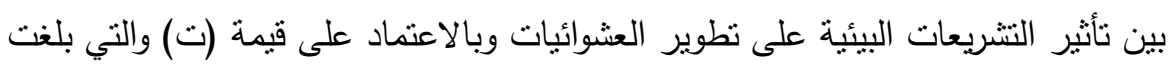

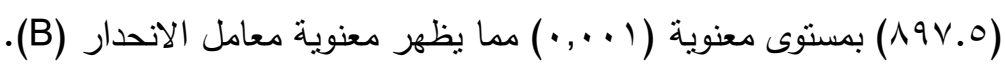

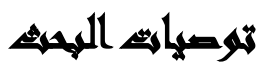

ه يوصي الباحثون بأهمية تفعيل التشريعات البيئية لتطوير العشوائيات بمحافظة القليوبية.

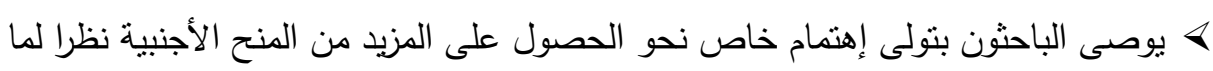
قدمته من فوائد ملحوظة في نطوير العثوائيات بمحافظة القليوبية.

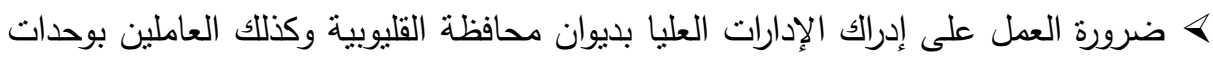
تطوير العشوائيات لأهمية التشريعات البيئية وكيفية اسثمار المنح الأجنبية على الوجة لإنية

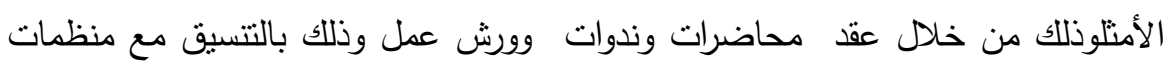
المجتمع المدنى لما لها من دور فعال ومردور إيجابى على الثارع المصرى.

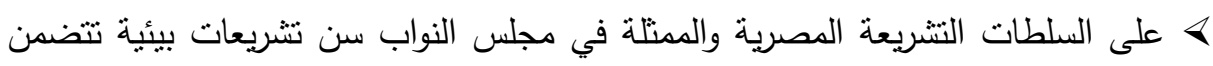
نصوص أكثر صرامة لرضع المواطنيين المتعدين على البيئة وذلك للقضاء على ظاهرة العشوائيات.

> العمل قدر المستطاع على تعزيز نوجيه موارد المنح الأجنبية نحو التتمية المستدامة.

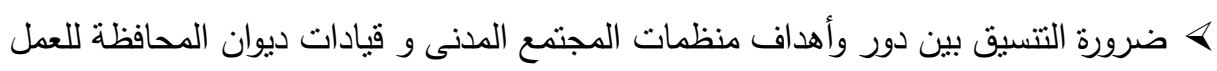
على قدم وساق نحو تطوير العشوائيات. ه يوصى الباحثون بضرورة إجراء بحوث مستقبيلة على العشوائيات بباقى محافظات جمهورية مصر العربية. 


\section{المرالئ}

إبراهيم، محمد (ع ( ب): مدى فاعلية النتريعات البيئية في حماية البيئة من المواد والنفايات الخطرة في القانون المصري، دراسة مالية مقارنة، رسالة دكتوراه معهد الدراسات البيأئية

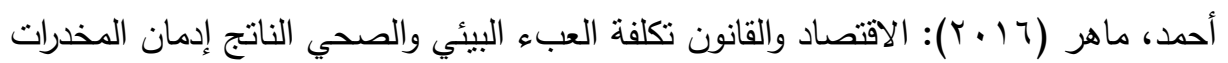

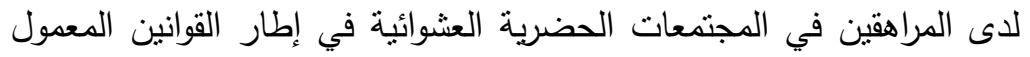

$$
\text { رسالة ماجسنير المراهني في }
$$

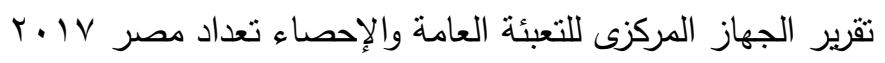
تقويم الباتلا صندوق تطويل المناطق العشوائية غير الأمنة.

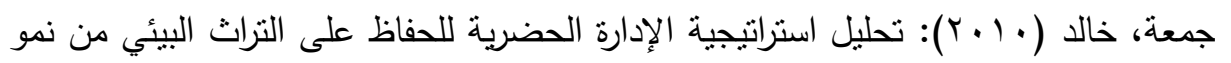

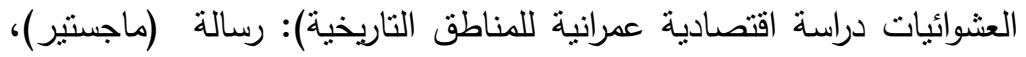
جامعة حلوان. كلية الخدمة الاجتماعية

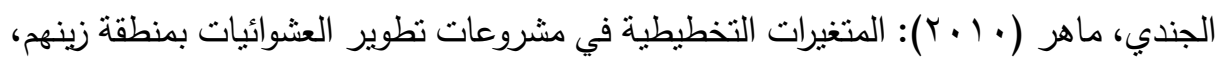

$$
\text { رسالة (دكتوراه) جامعة عين شمس، معهد الدراسات والبحوث }
$$

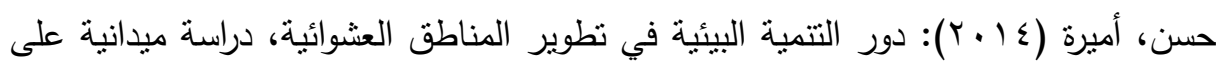

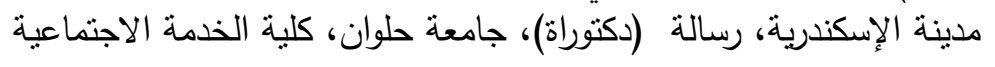

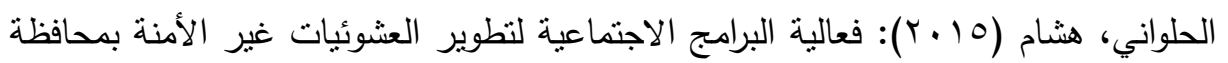

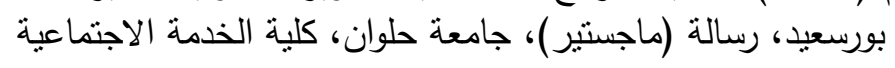

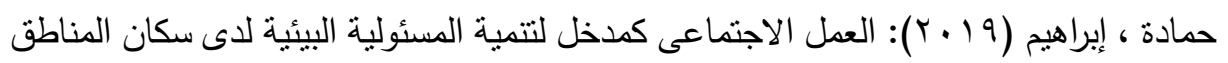

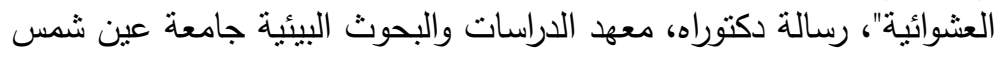

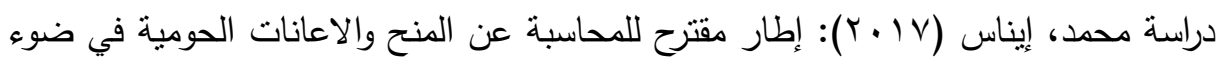

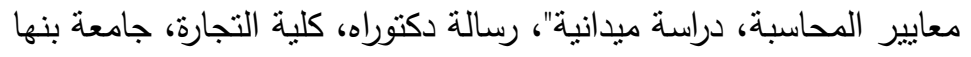

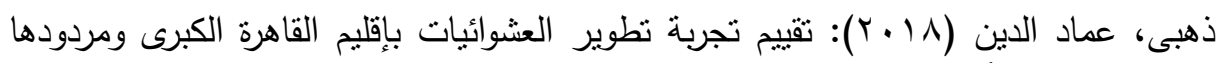

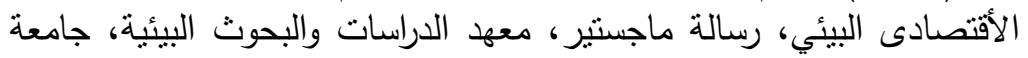

عين شمس الأفي

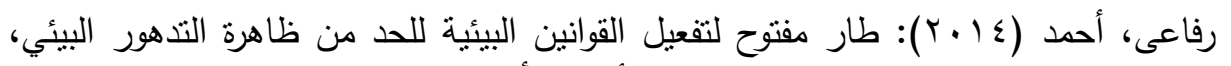

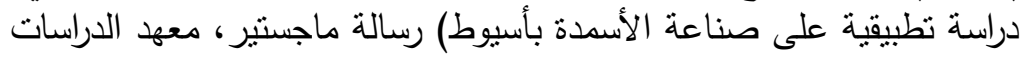

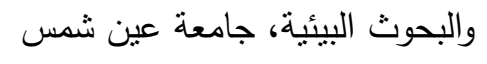


زعزوع، زينب (· • (†): دور المنح والمساعدات الأجنبية في تطوير المنظمات العامة في

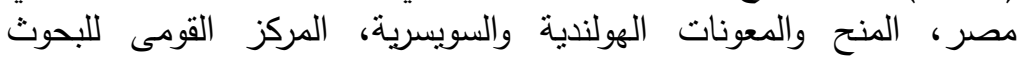
الاجنماعية والجنائية

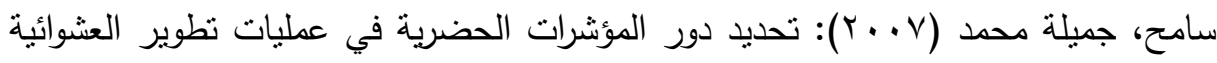

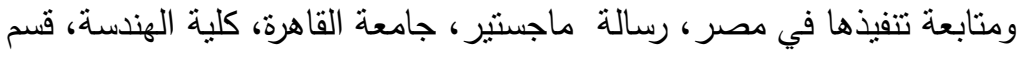

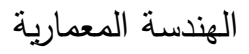

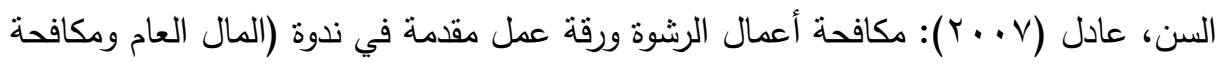

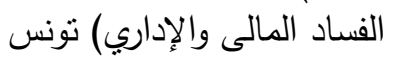

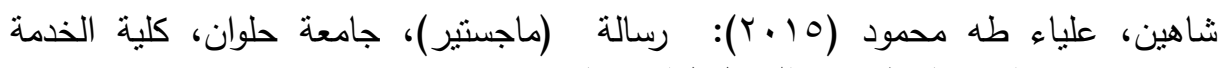

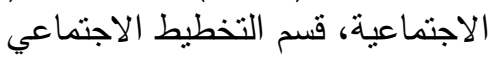

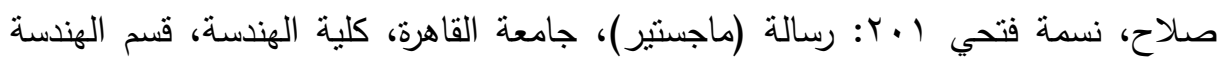

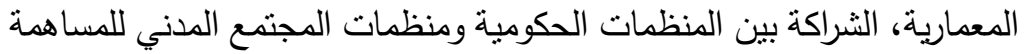
في تطوير العشوائيات

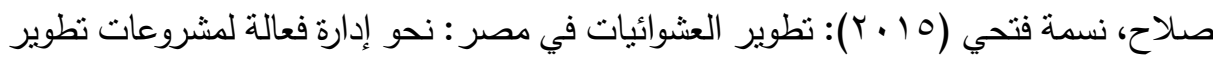
المناطق العشوائية، رسالة ماجستير ، جامعة القاهرة، كلية الهندسة، قسم الهندسة

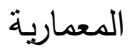

عبد الرحيم، مروة أحمد نبيل (r ( ץ): رسالة( دكتوراه)- معهد الدراسات والبحوث البيئية ،جامعة

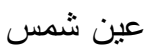

عثمان، محمد (10 (Y): العائد الاجتماعي والاقتصادي للبرامج الاجتماعية والاقتصادية

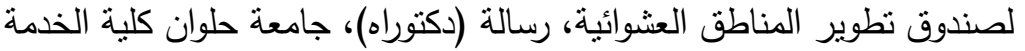

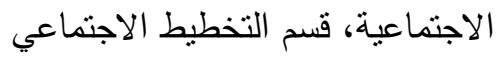

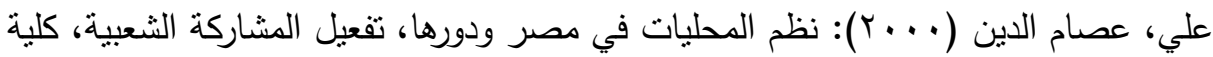

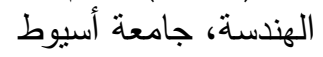

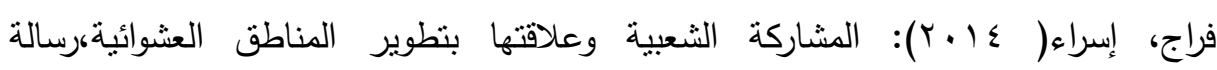

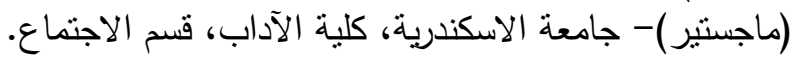

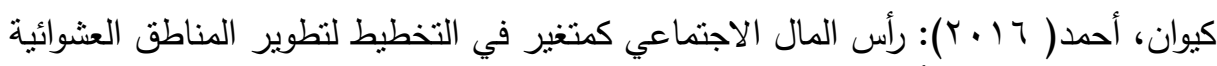

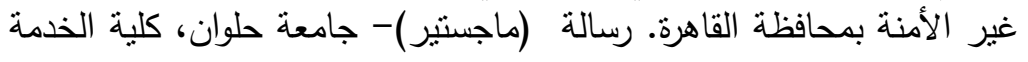

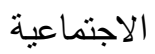




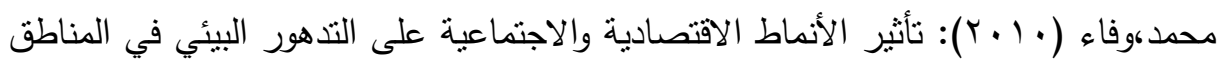

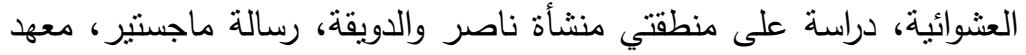

الدراسات والبحوث البيئية جامعة عين شمس عنم

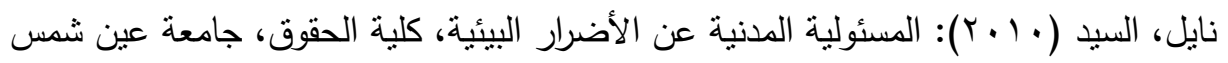

Almedia Rita \&Peter Carneiro,"The return to Firm investment in human capital "2006,Discussion Paper no.1937.PP.1-22.

Barpara Plomin Feled,academy Management journal,apkl,2001,P.64.

Charnes, A., W. W. Cooper et E. L. Rhodes, «Measuring the efficiency of decision making units». European Journal ofOperational Research, vol. 2, no 6, 1978; 429-444.

Cochrane,Policies For StrengThening For StrengThening Local government in developing Countries ,Washing Ton D.C USA, The world bank ,P.P40-44.

Debreu, G, « The Coefficient of Resource Utilization », Econometrica, vol. 19 (3), 1951; 273-292.

Environmental compliance in SMEs: an investigation into the legal performance of small and medium-sized enterprises (SMEs), encompassing compliance levels, the impact and effectiveness of environmental legislation and improving SME environmental compliance control systems

Farrell, J, The Measurement of Productive Efficiency », Journal of the Royal Statistical Society, Series A, vol. 120 (3), 1957; 253281.

Richard L.Daft and Ramond A.Noe,2001,P.16.

Thomas Bennett." A New Vision of Performance Evaluation Process:Afield Study and a la 


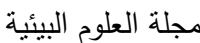

معهد الدراسات والبحوث البيئية - جامعة عين شمس لينان

\title{
EXAMINING THE EFFECTIVENESS OF ENVIRONMENTAL LEGISLATIONS AND FOREIGN DONATIONS FOR DEVELOPMENT OF SLUMS IN QALUBYIA GOVERNORATE
}

\author{
Maha G. El-Feshawy ${ }^{(1)}$; Atef A. Hassan ${ }^{(2)}$ \\ and Fouad A. Ibrahim (3)
}

1) Post Grad. Institute of Environments Studies and Research, Ain Shamas University 2) Faculty of Law, Ain Shams University 3) Future Academy.

\begin{abstract}
In fact, the phenomenon of slums in Egypt considers one of the most important challenges and wars Egypt has come through in the last few decades. Despite the difficulty of finding out an appropriate funding for getting rid of all slum areas, particularly, those are representing a critical risk on the their residents, the government has finally found out a way for appropriate funding. Likely, this dream of mot the political leaderships for years has become true. This study drives at achieving the principle of social justice on which the Revolution of 25 January, 2011 has been based upon through developing slums in Egypt and provide residents a good acceptable human life for all citizens, particularly, those residents of Qalubia governorate, the study area.

The study hypotheses indicates a significant correlation between activation of environment's regulations and foreign donations for developing slums in Qalubia governorate through activation of partnership between the donating states and the authority in charge represented in the Public Office of Qalubia governorate, the civil society institutions and the private sector. The study has used the descriptiveanalytical method for formulating the theoretical framework of study . Data are collected through two investigation forms as the study main
\end{abstract}

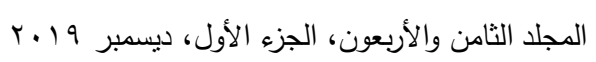


tools, one is directed to audience; while the other is directed to employees in Slums Development Units in Qalubia governorate. The sample consists of (18) workers in these Slums Development Units. The results indicate significant statistically correlation at (0.05) significance level between environmental legislations and slums' development. There is also a significant impact of environmental regulations on promotion of slums by $5.3 \%$. There is a statistically significant relationship at (0.05) significance level, as the environmental regulations affect the development of slum areas by $(10.7 \%)$.

The researchers recommend the importance of activating environmental legislations for developing slums in Qalubia governorate. The researchers have also recommended the necessity to ask for more foreign donations for the critical benefits these foreign aids have provided in developing slums in Qalubia governorate. 